\title{
Key Drivers behind the Development of Fluorocarbons Destruction Infrastructure: A Case Study of Japan
}

\author{
Yoshinori Morita $^{1} \&$ Toshikazu Shiratori ${ }^{2}$ \\ ${ }^{1}$ Environmental Protection Laboratory, DOWA ECO-SYSTEM CO., LTD, Akita, Japan \\ ${ }^{2}$ Graduate School of Environmental Studies, Tohoku University, Sendai, Japan \\ Correspondence: Yoshinori Morita, Environmental Protection Laboratory, DOWA ECO-SYSTEM CO., LTD, 65- \\ 1 Omoriyama-shita, Hanaoka, Odate, Akita 017-0005, Japan. Tel: 81-1-8646-2323. E-mail: moritay1@dowa.co.jp
}

Received: June 25, 2020

doi:10.5539/jsd.v14n2p27
Accepted: September 1, 2020

Online Published: February 5, 2021

URL: https://doi.org/10.5539/jsd.v14n2p27

\begin{abstract}
The Montreal Protocol has been ratified to progress phase-out of CFCs and HCFCs globally. HFCs have come into wide use as alternatives to CFCs and HCFCs, but as we know today, it was found that HFCs have a huge negative influence on global warming, and the Kigali Amendment to the Montreal Protocol entered into force to promote phase-down of HFCs. Since the enforcement of the Fluorocarbons Recovery and Destruction Law (F-gas law) in 2002, Japan has been undertaking fluorocarbons collection and destruction by environmentally-sound manners. However, no study has been reported investigates on how the Japanese fluorocarbons destruction infrastructure has been developed over the past several years. To analyze the development, we studied key drivers that contributed to encourage fluorocarbons collection from end of life electric appliances and to promote fluorocarbons destruction by environmentally and commercially sustainable technologies. We showed that recycling laws and the F-gas law have made progress in encourage fluorocarbons collection and destruction by making relevant stakeholders take physical and financial responsibilities for proper fluorocarbons disposal. This study also researched fluorocarbons destruction technologies that destruction operators used as of 2004 and 2019 , and found that three specific destruction technologies have long been used practically in Japan. Finally, we discussed influencing factors that have made these technologies accepted, installed and practically used by fluorocarbons destruction operators. In conclusion, we identified that existence of political frameworks as well as application of fluorocarbons destruction technologies that are commercially sustainable and socially acceptable were key drivers behind the development of fluorocarbons destruction infrastructure in Japan.
\end{abstract}

Keywords: fluorocarbons, fluorocarbons destruction, environmental political framework, electric appliance

\section{Introduction}

Inappropriate waste management has negative environmental consequences such as air pollution, water quality deterioration and soil contamination in our living environment, which may cause serious damage to human health and well-being. For instance, some studies investigated an association between exposures to landfill pollution and negative health effects of residence living near landfill sites (Mattiello et al., 2013; Rushton, 2003). Dioxins emission from incineration plant without proper gas treatment system has become an issue of major social concern in the past (Yoneda et al., 2002). Application of political frameworks and set up technical requirements and environment standards are important approaches to control health and environmental risks caused by waste management activities. Relatively strict special regulations are required for the management of hazardous waste and toxic substance due to their serious risks and negative impacts on surrounding environment. Similarly, for the management of fluorocarbons, the Montreal Protocol has established rules and criteria for appropriate fluorocarbons delivery and storage, and set a high destruction and removal efficiency (DRE) required for fluorocarbons destruction (UNEP, 2018).

Chlorofluorocarbons (CFCs), hydrochlorofluorocarbons (HCFCs), and hydrofluorocarbons (HFCs), commonly known as fluorocarbons, are compounds with specific properties such as non-flammability, thermal and chemical stability and dielectric property, and they are mainly used as refrigerants in cooling units of air-conditioning and refrigeration equipment (Yazici et al., 2014). CFCs and HCFCs phase-out and HFCs phase-down has been implemented or is being implemented under the Montreal Protocol after the findings of their deleterious effects on the ozone layer and negative contribution to the global warming (Molina and Rowland, 1974; Solomon, 1999; 
Mohanraj et al., 2009). To cope with the Kigali Amendment, the Japanese government has already taken actions to control HFCs manufacture and import, in addition, the country is promoting the development and introduction of low-global warming potential (GWP) / non-fluorocarbons refrigerants into new products (Skačanová and Battesti, 2019).

Recovering technology has been established to address used fluorocarbons collected from end of life (EoL) products. The process is to remove contaminants, moisture and oil from refrigerants by thermal processing, and the technology has become more important recently especially for HCFCs procurement as production and import of new HCFCs have been restricted after 2020 in Japan (Genta et al., 2017; Ohm et al., 2017). However, the recovering technology is not always the best approach for fluorocarbons disposal. In generally, recovery of fluorocarbons with high contaminants is not cost effective because of high quality standards (Note 1) required for recovered fluorocarbons (Devotta et al., 2004).

Destruction has been the main stream for fluorocarbons disposal in Japan. Fig.1 shows the amount of destructed and recovered fluorocarbons for the period of 2004 to 2018. Fluorocarbons are categorized by the disposal processes and type and usage of electric appliances that contained fluorocarbons. The amount of destructed fluorocarbons from household electric appliances had been at the same level for the period of 2004 to 2013, but it has been decreasing since 2013. This is because the F-gas law was revised in 2013 and license system for recovering business was introduced to encourage fluorocarbons recovery. The amount of destructed fluorocarbons from automobile air-conditioner has remained stable and recovery has not been carried out so far. The amount of destructed fluorocarbons from commercial/industrial electric appliances has been steadily increasing since 2004 despite fluorocarbons recovery has been implemented after 2014. Japanese government revised the F-gas law again in 2019 to strengthen fluorocarbons collection and promote refrigerants replacement to natural refrigerants with low-GWP, which would enhance social requirement to dispose useless fluorocarbons over the next few years.
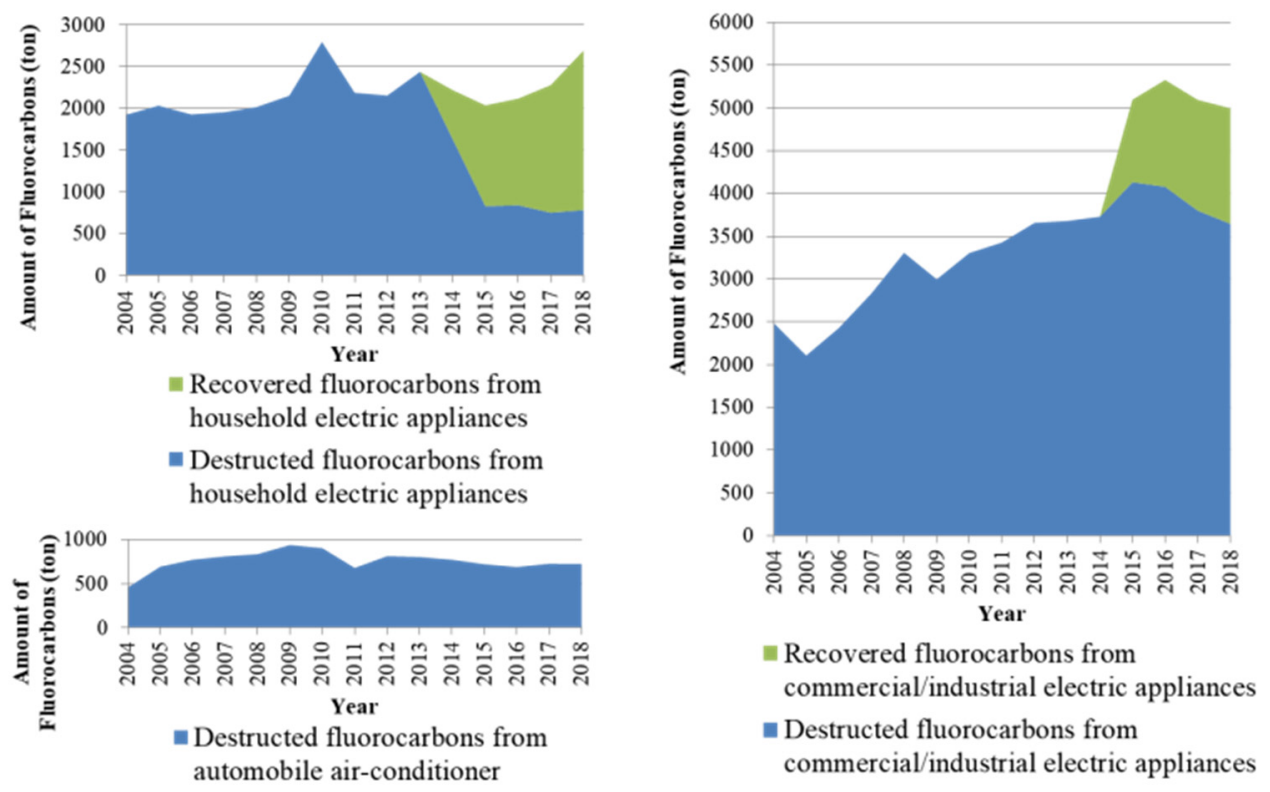

Figure 1. Fluorocarbons destruction and recovery in Japan

Source: Aggregate result, METI; Annual activity report, AEHA.

It has been about two decades since the F-gas law entered into force in Japan, but studies focus on the development of fluorocarbons destruction infrastructure have not been carried out before. Because of this, the main objective of this study was to identify key drivers that have contributed to develop the destruction infrastructure in Japan. Firstly, we researched frameworks of recycling laws and the F-gas law in order to find out how policy instruments work to establish proper fluorocarbons collection and destruction. Secondly, this study tried to research fluorocarbons destruction technologies practically used by destruction operators in the past and present, and discussed influencing factors that have made these technologies commercially available. Understanding the key drivers may make other countries get benefits to strength their fluorocarbons management. What is more, better 
understanding of good and bad practices behind the development of the destruction infrastructure would help make plans and strategies for fluorocarbons management in Japan over the next few years.

\section{Political Framework}

According to type and usage of products, different political frameworks have been applied to fluorocarbons disposal in Japan. Home Appliance Recycling Law came into force in 2001 and the law obligates manufacturers and importers of 4 categories of electric appliances (Air-conditioner, TV set, Electric refrigerator and freezer, Electric washing machine and clothes dryer) to collect and recycle the household electric appliances which they manufactured or imported (Hotta et al., 2014, 2016). The recycling law also obligates manufacturers and importers to collect and recovery or destruct fluorocarbons used in air-conditioner, refrigerator and freezer, insulation foam of refrigerator and freezer (Hotta et al., 2014). EoL Vehicle Recycling Law has been enforced since 2002, and this law obligates automobile manufacturers and importers to collect shredder residue, airbag and fluorocarbons from EoL vehicle to secure recycling or disposal (Hiratsuka et al., 2014). One of the good practices of the recycling laws is to define financial and physical responsibilities of relevant stakeholders. In particular, consumers are responsible for paying collection and recycling costs, and delivering EoL products to licensed/permitted collector. Hence, fluorocarbons contained in EoL products are transferred to recovery or destruction operators through collection and dismantling processes without being released into atmosphere (Scheutz, et al., 2010).

There is no specific recycling law targeting on air-conditioner, refrigerator and freezer used in commercial/industrial activities, and the electric appliances are handled as wastes when disposed by users. However, the F-gas law obligates users of commercial/industrial electric appliances to perform periodic maintenance and leak checking and to take financial and physical responsibilities for fluorocarbons disposal (MOE, 2019a). As the focus of the F-gas law is to provide appropriate fluorocarbons management throughout whole lifecycle, it encourages fluorocarbons manufacturers to develop low-GWP / non-fluorocarbons refrigerants and encourages electric products manufacturers to use the environmentally friendly refrigerants in new products. The government has revised the F-gas law in 2019 to improve fluorocarbons collection rate by imposing a fine to users who do not fulfill user's responsibility properly. The law also defines roles and responsibilities of recovery and destruction operators. Operators have to get a recovery or destruction license from central government, and to get the approval, structure of facility, recovering performance or DRE of the facility, operation and maintenance conditions have to meet technical standards prescribed under the F-gas law.

\section{Fluorocarbons Destruction Technology}

The F-gas law stipulates available fluorocarbons destruction technologies for destruction operators. The UNEP Technology and Economic Assessment Panel has approved 15 technologies for CFCs and HCFCs destruction, and application of the technologies for HFCs and Halons destruction is partially under discussion (UNEP, 2018). In accordance with the technology assessment, the Japanese F-gas law categorized these technologies into 7 technologies. The fluorocarbons destruction technologies and its technological characteristic are shown in Table 1 (UNEP, 2002, 2018; MOE, 2006).

Fluorocarbons destruction operators are admitted to select any technologies as long as they satisfy the DRE of 99.99\%, but there are lots of discussions on the selection of the best available technology. UNEP (2018) mentioned that a great advantage of incinerator is its ability to handle a wide variety of wastes, while they also argued that construction of new incinerator with the intension of destroying fluorocarbons only is challenging due to high cost of construction and maintenance. Takita and Ishihara (1998) argued risk of dioxins formation caused by fluorocarbons combustion in incinerator. Cement kiln processing has a high fluorocarbons processing capacity, but cement kiln has a limited tolerance for chlorine and fluorine and fluorocarbons feeding needs to be controlled to prevent process disturbances and negative impacts on cement quality (Karstensen et al., 2014). Incinerator with submerged combustion can address a wide range of liquid or vapor wastes, while application of the technology for solid waste disposal is very limited (Knox, 2005; UNEP, 2002). Plasma technology shows a high DRE and has a potential for halogens recycling by fixing them to Ca-compounds whereas the technology requires high energy consumption (Chang, 2001; Murphy et al., 2002). Although a high decomposition rate of catalytic dehalogenation has been achieved, periodic recovery of catalyst is required while operation due to catalyst deactivation caused by reaction with hydrogen fluoride (Ng et al., 1998; Takita and Ishihara, 1998). Superheated steam reaction has a high DRE, low pollutants emissions and a space-saving design of the facility, but the technology is used only for fluorocarbons destruction. Fundamental processes are different among these technologies, but in most cases, the destruction is achieved by making fluorocarbons converted into species such as $\mathrm{CO}_{2}, \mathrm{HX}$ or $\mathrm{X}_{2}(\mathrm{X}=\mathrm{Br}, \mathrm{Cl}, \mathrm{F})$ and neutralizing them to be harmless and environmentally benign materials.

Generally, different waste management technologies display different technical and environmental characteristics, 
and economic situation or other specific conditions may cause different outputs on the technology performance (Generowicz et al., 2011; Karagiannidis and Moussiopoulos, 1998). The assumption made from this perspective was that several factors have influenced on the selection of fluorocarbons destruction technologies, and as a consequence of this, current Japanese destruction infrastructure has been developed over past two decades. There are vast literatures addressing influencing factors in making waste management technologies that are socially accepted, installed and practically operated with technic and economic sustainability. Rafiee et al. (2016) argued technical sustainability, economic advantage, social acceptance and environmental risk management as main criteria for screening of applicable waste management technology. In addition to that, Parekh et al. (2015) and Kim et al. (2013) focused on resource conservation efficiency in disposal technology, efficiency in waste collection and transportation, consumer's compliant and satisfaction. Gu et al. (2019) evaluated E-waste disposing technology from perspective of energy consumption and environmentally friendly advantages. Fu et al. (2018) emphasized possibilities of further technological innovation addressing new materials that might be contained in products in the future. Rajendran et al. (2019) discussed the importance of user's skill and capacity for sustainable facility operation.

Table 1. Fluorocarbons destruction technologies under the F-gas law in Japan

\begin{tabular}{|c|c|}
\hline Destruction Technology & Technological Characteristic \\
\hline Incineration with waste & $\begin{array}{l}\text { Fluorocarbons are fed into incinerator with other types of wastes and } \\
\text { destroyed at a temperature more than } 850^{\circ} \mathrm{C} \text {. }\end{array}$ \\
\hline $\begin{array}{l}\text { Destruction in manufacturing } \\
\text { process }\end{array}$ & $\begin{array}{l}\text { Fluorocarbons are charged into manufacturing process (e.g., lime } \\
\text { calcinations furnace, cement kiln) and destructed by the process heat at } \\
\text { a temperature more than } 1,000^{\circ} \mathrm{C} \text {. }\end{array}$ \\
\hline Submerged combustion & $\begin{array}{l}\text { Fluorocarbons are atomized into vertical incinerator at more than 1,200 } \\
{ }^{\circ} \mathrm{C} \text { and flue gas is injected into water in cooling vessel. }\end{array}$ \\
\hline Plasma & $\begin{array}{l}\text { Fluorocarbons are mixed with plasma jet and rapidly heated in the } \\
\text { reaction chamber at about } 2,500^{\circ} \mathrm{C} \text {. }\end{array}$ \\
\hline Catalytic dehalogenation & $\begin{array}{l}\text { Fluorocarbons are decomposed chemically in contact with catalysts } \\
\text { such as } \mathrm{CrO}_{3}, \mathrm{ZrO}_{2}, \mathrm{TiO}_{2} \text { and } \mathrm{Al}_{2} \mathrm{O}_{3} \text { at } 400-500^{\circ} \mathrm{C} \text {. }\end{array}$ \\
\hline Superheated steam reaction & $\begin{array}{l}\text { Fluorocarbons are decomposed in reaction with superheated vapor at a } \\
\text { temperature within a range of } 850-1,000^{\circ} \mathrm{C} \text {. }\end{array}$ \\
\hline Other technologies & $\begin{array}{l}\text { Other technologies are available if the government admits its } \\
\text { performance and capacity. }\end{array}$ \\
\hline
\end{tabular}

\section{Analysis}

\subsection{Research Methodology}

We utilized Japanese government's open data and websites of destruction operators and implemented questionnaire surveys in order to investigate fluorocarbons destruction technologies used by destruction operators on commercial basis (MOE, 2006; MOE, 2019b). A study report compiled by the Ministry of the Environment has researched fluorocarbons destruction technologies used by destruction operators as of 2004 (MOE, 2006). Operators with the fluorocarbons destruction license are registered on the government database. By utilizing this registration list, we checked websites of all registered operators and carried out questionnaire surveys to collect information about the destruction technologies that was used as of 2019.

To support the discussion on influencing factors that made destruction technologies commercially available, we classified destruction operators into 6 business groups by the main business activities: ( $i$ )Waste management service provider, (ii )Fluoroproducts manufacturer, (iii)Industrial gas supplier, (iv)Air-conditioning maintenance service provider, ( $\mathrm{v}$ )Fluorocarbons specialized service provider, (vi)Other services provider. The aim of this categorization was to research how their main business activities influenced on destruction technologies they have installed. Destruction operators categorized in waste management service provider offer waste transportation, segregation, recycling and incineration services. Fluoroproducts manufacturer works mainly on development, 
manufacture and sale of fluorochemical materials and fluoropolymers. Industrial gas supplier produces and supplies various gases for industrial activities. Destruction operators classified in air-conditioning maintenance service provider offer inspection and maintenance services on air-conditioner used in house and commercial building. Fluorocarbons specialized service provider means professional service provider working on fluorocarbons removal from EoL products and fluorocarbons disposal. The classification was done by seeing company profile, and some destruction operators were classified into (vi)Other services provider when their main business was unclear or difficult to be classified into defined 5 business groups. This classification was carried out for destruction operators registered on the government database as of 2019.

\subsection{Research Result}

Table 2 shows the number of fluorocarbons destruction operators categorized by destruction technology. In 2004, two years after the F-gas law was enforced, there were 82 destruction operators in Japan. Despite destruction operators were admitted to install any technologies listed on the F-gas law, this research found that many destruction operators installed either incineration with waste, plasma, or superheated steam reaction, while only one destruction operator introduced catalytic dehalogenation. The total number of destruction operators has decreased by 2019. Incineration with waste and superheated steam reaction were still major fluorocarbons destruction technologies but plasma destruction was already not being used practically. It was surprising because plasma technology demonstrated a high DRE and processing capacity and there was the fact that plasma had been the major destruction technology in 2004 (Ohno et al., 2007; Sekiguchi et al., 1993; UNEP, 2002). In addition, there were 7 destruction operators using cement kiln for fluorocarbons destruction in 2004, but cement kiln has become used less often by 2019. Submerged combustion has long been used until today and the number of destruction operators has not been changed over the past few years.

Table 2. Number of fluorocarbons destruction operators categorized by destruction technology

\begin{tabular}{|c|c|c|c|c|}
\hline \multirow[t]{2}{*}{ Category } & \multicolumn{2}{|c|}{ Fluorocarbons Destruction Technology } & \multicolumn{2}{|c|}{$\begin{array}{l}\text { Number of } \\
\text { Operators }\end{array}$} \\
\hline & & & 2004 & 2019 \\
\hline \multirow{4}{*}{$\begin{array}{l}\text { Multipurpose } \\
\text { system }\end{array}$} & Incineration with waste & $\begin{array}{l}\text { Rotary kiln incinerator, Gasification } \\
\text { and melting furnace }\end{array}$ & 24 & 20 \\
\hline & \multirow{3}{*}{$\begin{array}{l}\text { Destruction in } \\
\text { manufacturing process }\end{array}$} & Cement kiln & 7 & 1 \\
\hline & & Electric furnace & 1 & 2 \\
\hline & & Lime calcination furnace & 0 & 1 \\
\hline \multirow{8}{*}{$\begin{array}{l}\text { Devoted } \\
\text { system }\end{array}$} & \multirow{2}{*}{ Submerged combustion } & Gaseous / fume oxidation & \multirow{2}{*}{7} & \multirow{2}{*}{7} \\
\hline & & Liquid injection incineration & & \\
\hline & \multirow{3}{*}{ Plasma } & Radio frequency plasma & 1 & 0 \\
\hline & & Plasma arc & 8 & 1 \\
\hline & & Microwave plasma & 8 & 0 \\
\hline & Catalytic dehalogenation & Gas phase catalytic dehalogenation & 1 & 0 \\
\hline & $\begin{array}{l}\text { Superheated steam } \\
\text { reaction }\end{array}$ & Superheated steam reactor & 25 & 21 \\
\hline & \multicolumn{2}{|l|}{ Other technologies } & 0 & 1 \\
\hline \multicolumn{3}{|l|}{ Unknown } & 0 & 4 \\
\hline \multicolumn{3}{|l|}{ Total } & 82 & 58 \\
\hline
\end{tabular}

The fluorocarbons destruction operators as of 2019 were classified into 6 business groups based on their main business activities, and the relationship between the fluorocarbons destruction technologies and the main business activities is shown in Fig.2. As expected, incineration with waste was the destruction technology introduced by many waste management service providers. In detail, it was found that 13 of 19 waste management service providers used rotary kiln incinerator, the facility suitable in destroying hazardous waste and toxic substance 
because of its wide adaptability for various types of wastes (Jiang et al., 2019). It was particularly interesting that submerged combustion has been installed only by fluoroproducts manufacturers and no other destruction operators used the technology. Fig. 2 also shows that superheated steam reaction has been installed by several destruction operators regardless of differences in the main business activities. Waste management service providers that work mainly on segregation and metal recycling installed superheated steam reactor instead of incinerator. Superheated steam reaction was also the common technology among industrial gas suppliers, air-conditioning maintenance service providers and fluorocarbons specialized service providers. This data imply superheated steam reaction would be the fluorocarbons destruction technology that destruction operators even without specialized knowledge and skills for operation can easily install and use it practically.

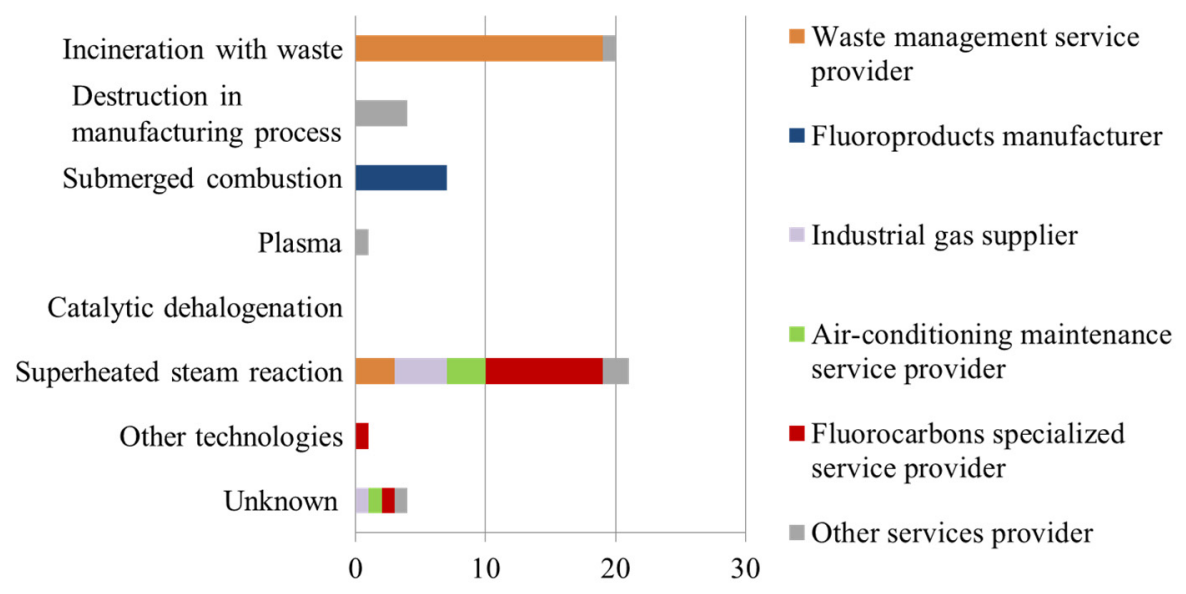

Figure 2. Relationship between fluorocarbons destruction technologies and the main business activities of destruction operators in 2019

\section{Discussion}

The recycling laws in Japan secure proper and smooth collection and environmentally-sound disposal of fluorocarbons by implementing efficient collection and transportation of EoL household electric appliances and automobiles and promoting recycling of the products. The F-gas law secures proper collection and disposal of fluorocarbons used in commercial/industrial electric appliances, and the law also set technical standards and requirements that fluorocarbons recovery and destruction operators have to follow. As waste collection is a critical first step in managing waste, the political frameworks has made a great contribution to the development of fluorocarbons destruction infrastructure by defining financial and physical responsibilities of relevant stakeholders and encouraging disposers to deliver EoL products or fluorocarbons to reliable collectors (World Bank, 2018). However, it is worth noting that even such political frameworks do not cover the collection of all fluorocarbons generated in the country. It was reported that used household electric appliances have been exported to Asian countries (Brebbia, 2014; Zeng, 2017). In addition, under the current political frameworks, electric appliances such as dehumidifier and fan cooler are allowed to be shredded for metal recycling objective or disposed into landfill site even though they contain fluorocarbons. This situation suggests that there is yet space for improvement in fluorocarbons collection in Japan.

Regarding to the fluorocarbons destruction technology, incineration with waste, submerged combustion and superheated steam reaction were identified as the major technologies that have long been used in Japan despite several different types of destruction technologies are admitted as reliable technologies under the F-gas law. By reviewing characteristics of each technology and the main business activities of destruction operators, we discussed influencing factors that have made the three technologies accepted, installed and practically used on commercial basis in Japanese fluorocarbons destruction infrastructure.

Firstly, we hypothesized that the three technologies have an economic advantage over other destruction technologies. Incineration with waste has been used mostly by waste management service providers, and this would be because destruction operators were able to save initial cost when they utilized existing waste incinerator for fluorocarbons destruction. Submerged combustion is commonly used in industry for on-site treatment and this study identified that only fluoroproducts manufacturers installed the technology (USEPA, 2008). Fluorocarbons are used as precursors for fluoropolymers, therefore, it is expected that a large amount of useless fluorocarbons 
generated in fluoroproducts manufacturing sites (Ebnesajjad, 2013). Fluoroproducts manufacturers would be able to cut fluorocarbons disposal cost when they are operating facility on their own rather than offering the disposal to waste management contractor. Superheated steam reaction has an advantage in destruction cost. UNEP (2002) researched cost comparison between fluorocarbons destruction technologies and it reported that destruction cost of the superheated steam reaction was in the range of \$US 1.1-1.4/kg-CFCs, this is much cheaper than the cost of plasma and incineration with waste (\$US 3-5/kg-CFCs).

Another expected influencing factor is social acceptability of the each technology. Waste incinerator has been the major facility for hazardous waste disposal and many studies have been carried out to evaluate fluorocarbons destruction ability of incinerators even before the enforcement of the F-gas law (Tokuhashi et al., 1990; Francis and Michael, 1998; Urano et al., 1997). Hence, it would be natural consequence that incineration plant has become the major fluorocarbons destruction technology. Submerged combustion was developed under government initiative in collaboration with fluoroproducts manufacturers aimed to destruct HFCs efficiently (NEDO, 2012). Superheated steam reaction was the technology that Japanese company has developed, which would make various destruction operators relied on and accepted the technology. Moreover, the facility is typically simple, compact and space-saving device specialized in decomposing fluorocarbons, which would be attractive for destruction operators because they are able to install and use the facility without worrying excessively about space for installation and operation skills.

When comparing the total number of fluorocarbons destruction operators between 2004 and 2019, it was found that 24 destruction operators including 16 operators with plasma technology have discontinued fluorocarbons destructing service. As the total amount of destructed fluorocarbons in this period was constant (see Fig.1), it can be assumed that competition took place among destruction operators. Cement production has been decreasing since 1996 in Japan, and this would be the reason why cement kiln has already been out of use commercially for fluorocarbons destruction (Lamas et al., 2013; Huang et al., 2012; JCASSOC, 2019). The number of destruction operators with plasma technology might has decreased as a result of cost competition with destruction operators with superheated steam reaction. Besides, there is a possibility that some destruction operators failed to meet technical standards or to fulfill responsibilities obligated under the F-gas law.

\section{Conclusion}

In this study, we researched recycling laws and the F-gas law in Japan and confirmed that the political frameworks have been contributing to secure fluorocarbons collection from EoL products and promote fluorocarbons destruction by environmentally-sound manners. The analysis on fluorocarbons destruction technology showed that the country relies mainly on three destruction technologies: incineration with waste, submerged combustion and superheated steam reaction. In addition, we discussed how economic advantage and social acceptance of destruction technology influenced to make the three technologies accepted, installed and practically used in Japan. Hence, we concluded that the existence of political frameworks as well as application of destruction technologies that are commercially sustainable and socially acceptable were key drivers for the development of fluorocarbons destruction infrastructure in Japan.

Understanding the key drivers would be able to share knowledge and good practices among countries with undeveloped fluorocarbons destruction infrastructure. Development of political frameworks securing fluorocarbons collection and transportation and defining financial responsibilities of relevant stakeholders is highly recommended. Fluorocarbons destruction technology should obtain financial advantage and social acceptability, otherwise the technology may become out of use after installation. Cement kiln are already in place even in emerging countries, therefore, fluorocarbons destruction by cement kiln would be a good approach for those countries. However, we recommend not depending heavily on cement kiln for fluorocarbons disposal due to the fluorocarbons feeding limit of cement kiln for the prevention of process disturbances and cement quality deterioration. Developing countries tend to depend on landfilling for waste disposal today, but they would install incineration plant in the future through industrialization and economic progress. In this point, fluorocarbons destruction by incineration with waste might become the major destruction technology in such countries.

In Japan, it can be expected that the demand for fluorocarbons destruction would be increasing in the short term due to the promotion of refrigerant replacement and the improvement of fluorocarbons collection rate. However, from a long-term perspective, the destruction demand would decrease in accordance with the expansion of fluorocarbons recovery and HFC phase-down. Hence, effective use of existing facility would be a cost-saving approach to deal with fluorocarbons generated in next few years rather than construction of new destruction facility. Since submerged combustion and superheated steam reaction are designed technologies specialized to fluorocarbons destruction, destruction operators with the technologies may struggle to collect enough 
fluorocarbons for continuous operation over the next few years. From this perspective, destruction operators undertaking incineration with waste would have an advantage over other technologies because their main business is to combust wastes and fluorocarbons destruction is just a one of the services.

\section{Acknowledgements}

We acknowledge Mr. Ryoei Watanabe for his contribution in enhancing the quality of this paper.

\section{Reference}

AEHA (Association for Electric Home Appliances). Annual activity report on home appliance recycling, Year 2004 version to Year 2018 version (in Japanese).

Brebbia, C. A., Passerini, G., \& Itoh, H. (2014). Waste Management and the Environment VII. WIT press, pp. 314.

Chang, J. S. (2001). Recent development of plasma pollution control technology: a critical review. Science and Technology of Advanced Materials, 2(3-4), 571-576. https://doi.org/10.1016/S1468-6996(01)00139-5

Devotta, S., Asthana, S., \& Joshi, R. (2004). Challenges in recovery and recycling of refrigerants from Indian refrigeration and air-conditioning service sector. Atmospheric Environment, 38(6), 845-854. https://doi.org/10.1016/j.atmosenv.2003.10.039

Ebnesajjad, S. (2013). Introduction to Fluoropolymers: Materials, Technology and Applications. PDL handbook series, pp. 91-118.

Francis, H. W. W., \& Michael, K. P. (1998). Presentation at ANACON 98· the Asian·North American Solid Waste Management Conference \& Exhibit. Retrieved June 16, 2020, from http://www.seas.columbia.edu/earth/wtert/sofos/nawtec/anacon98/anacon98-19.pdf/

Fu, J., Zhang, H., Zhang, A., \& Jiang, G. (2018). E-waste Recycling in China: A Challenging Field. Environmental Science and Technology. 52, 6727-6728. https://doi.org/10.1021/acs.est.8b02329

Generowicz, A., Kulczycka, J., Kowalski, Z., \& Banach, M. (2011). Assessment of waste management technology using BATNEEC options, technology quality method and multi-criteria analysis. Journal of Environmental Management, 92(4), 1314-1320. https://doi.org/10.1016/j.jenvman.2010.12.016

Genta, C., Marotta, C., \& Migliardini, F. (2017). Study and Development of a Complete System for Recovery, Recycle, and Disposal of Refrigerant Gas from Existent Plants. Journal of Engineering, 1-9. https://doi.org/10.1155/2017/9202185

Gu, W., Bai, J., Feng, Y., Zhang, C., Wang, J., Yuan, W., \& Shih, K. (2019). Chapter 9 - Biotechnological Initiatives in E-waste Management: Recycling and Business Opportunities. Electronic Waste Management and Treatment Technology, 201-223. https://doi.org/10.1016/B978-0-12-816190-6.00009-1

Hiratsuka, J., Sato, N., \& Yoshida, H. (2014). Current status and future perspectives in end-of-life vehicle recycling in Japan. Journal of Material Cycles and Waste Management, 16, 21-30. https://doi.org/10.1007/s10163-0130168-z

Hotta, Y., Santo, A., \& Tasaki, T. (2014). EPR-based Electronic Home Appliance Recycling System under Home Appliance Recycling Act of Japan. OECD publishing. Retrieved June 16, 2020, from http://www.oecd.org/environment/waste/EPR_Japan_HomeAppliance.pdf/

Hotta, Y., Visvanathan, C., Kojima, M., \& Pariatamby, A. (2016). Developing 3R policy indicators for Asia and the Pacific region: experience from Regional 3R Forum in Asia and the Pacific. Journal of Material Cycles and Waste Management, 18, 22-37. https://doi.org/10.1007/s10163-015-0442-3

Huang, Q., Yang, Y., \& Wang, Q. (2012). Potential for Serious Environmental Threats from Uncontrolled Coprocessing of Wastes in Cement Kilns. Environmental Science \& Technology, 46, 13031-13032. https://doi.org/10.1021/es3042274

JCASSOC (Japan Cement Association). (2019). Cement Handbook (in Japanese). Retrieved June 18, 2020, from http://www.jcassoc.or.jp/cement/4pdf/jj3h_06.pdf/

Jiang, X., Li, Y., \& Yan, J. (2019). Hazardous waste incineration in a rotary kiln: a review. Waste Disposal \& Sustainable Energy, 1, 3-37. https://doi.org/10.1007/s42768-019-00001-3

Karagiannidis, A., \& Moussiopoulos, N. (1998). A model generating framework for regional waste management taking local peculiarities explicitly into account. Location Science, 6(1-4), 281-305. https://doi.org/10.1016/S0966-8349(98)00052-7 
Karstensen, K. H., Parlikar, U. V., Ahuja, D., Sharmab, S., Chakraborty, M. A., Maurya, H. P., .. Kapadia, B. V. (2014). Destruction of concentrated chlorofluorocarbons in India demonstrates an effective option to simultaneously curb climate change and ozone depletion. Environmental Science \& Policy, 38, 237-244. https://doi.org/10.1016/j.envsci.2014.01.008

Kim, M., Jang, Y., \& Lee, S. (2013). Application of Delphi-AHP methods to select the priorities of WEEE for recycling in a waste management decision-making tool. Journal of Environmental Management, 128, 941948. https://doi.org/10.1016/j.jenvman.2013.06.049

Knox, A. (2005). An Overview of Incineration and EFW Technology as Applied to the Management of Municipal Solid Waste (MSW). Retrieved June 16, 2020, from https://www.researchgate.net/publication/237654041_An_Overview_of_Incineration_and_EFW_Technolog y_as_Applied_to_the_Management_of_Municipal_Solid_Waste_MS̄W/

Lamas, W. Q., Palau, J. C. F., \& Camargo, J. R. (2013). Waste materials co-processing in cement industry: Ecological efficiency of waste reuse. Renewable and Sustainable Energy Reviews, 19, 200-207. https://doi.org/10.1016/j.rser.2012.11.015

Mattiello, A., Chiodini, P., Bianco, E., Forgione, N., Flammia, I., Gallo, C., ... Panico, S. (2013). Health effects associated with the disposal of solid waste in landfills and incinerators in populations living in surrounding areas: a systematic review. International Journal of Public Health, 58(5), 725-35. https://doi.org/10.1007/s00038-013-0496-8

METI (Ministry of Economy, Trade and Industry). Aggregate results of recovered and destructed fluorocarbons, FY2004 to FY2018.

MOE (Ministry of the Environment). (2006). The Study on ODS Disposal Options in Article 5 Countries. Retrieved June 17, 2020, from https://www.env.go.jp/en/earth/ozone/ods2006.pdf/

MOE (Ministry of the Environment). (2019a). Use's guideline under Revised F-Gas Law in Japan (in Japanese). Retrieved June 17, 2020, from http://www.env.go.jp/earth/ozone/cfc/law/kaisei_r01/attach/R02-kanrihdbk_Rev02_Full\%20.pdf/

MOE (Ministry of the Environment). (2019b). A list of licensed destruction operator (in Japanese). Retrieved June 17, 2020, from https://www.env.go.jp/earth/ozone/cfc.html/

Mohanraj, M., Jayaraj, S., \& Muraleedharan, C. (2009). Environment friendly alternatives to halogenated refrigerants-a review. International Journal of Greenhouse Gas Control, 3(1), 108-119. https://doi.org/10.1016/j.ijggc.2008.07.003

Molina, M. J., \& Rowland, F. S. (1974). Stratospheric sink for chlorofluoromethanes: chlorine atom-catalysed destruction of ozone. Nature, 249(5460), 810-812. https://doi.org/10.1038/249810a0

Murphy, A. B., Farmer, A. J. D., Horrigan, E. C., \& McAllister, T. (2002). Plasma Destruction of Ozone Depleting Substances. Plasma Chemistry and Plasma Processing, 22, 371-385. https://doi.org/10.1023/A:1015365032020

NEDO (New Energy and Industrial Technology Development Organization). (2012). NEDO project success story (in Japanese). Retrieved June 17, 2020, from https://www.nedo.go.jp/hyoukabu/articles/201113tsukishima/

Ng, C. F., Shan, S., \& Lai, S. Y. (1998). Catalytic decomposition of CFC-12 on transition metal chloride promoted $\gamma$-alumina. Applied Catalysis B: Environmental, 16(3), 209-217. https://doi.org/10.1016/S09263373(97)00075-1

Ohm, T., Myung, S., Jang, W., \& Yu, S. (2017). A comparison of refrigerant management policies and suggestions for improvement in South Korea. Journal of Material Cycles and Waste Management, 19, 631-644. https://doi.org/10.1007/s10163-015-0455-y

Ohno, M., Ozawa, Y., \& Ono, T. (2007). Decomposition of HFC134a Using Arc Plasma. International Journal of Plasma Environmental Science \& Technology, 1(2), 159-165. Retrieved June 16, 2020, from http://www.iesj.org/content/files/pdf/vol1_no2_2007/IJPEST_Vol1_No2_09_pp159-165.pdf/

Parekh, H., Yadav, K., Yadav, S., \& Shah, N. (2015). Identification and assigning weight of indicator influencing performance of municipal solid waste management using AHP. KSCE Journal of Civil Engineering, 19, 3645. https://doi.org/10.1007/s12205-014-2356-3

Rafiee, A., Yaghmaeian, K., Hoseini, M., Parmy, S., Mahvi, A., Yunesian, M., ... Nabizadeh, R. (2016). Assessment and selection of the best treatment alternative for infectious waste by modified Sustainability 
Assessment of Technologies methodology. Journal of Environmental Health Science and Engineering, 14(10). https://doi.org/10.1186/s40201-016-0251-1

Rajendran, K., Lin, R., Wall, D. M., \& Murphy, J. D. (2019). Chapter 5 - Influential Aspects in Waste Management Practices. Sustainable Resource Recovery and Zero Waste Approaches, 65-78. https://doi.org/10.1016/B9780-444-64200-4.00005-0

Rushton, L. (2003). Health hazards and waste management. British Medical Bulletin, 68(1), 183-197. https://doi.org/10.1093/bmb/ldg034

Scheutz, C., Fredenslund, A. M., Nedenskov, J., \& Kjeldsen, P. (2010). Release and fate of fluorocarbons in a shredder residue landfill cell: 2. Field investigations. Waste Management, 30(11), 2163-2169. https://doi.org/10.1016/j.wasman.2010.03.033

Sekiguchi, H., Honda, T., \& Kanzawa, A. (1993). Thermal plasma decomposition of chlorofluorocarbons. Plasma Chemistry and Plasma Processing, 13, 463-478. https://doi.org/10.1007/BF01465876

Skačanová, K. Z., \& Battesti, M. (2019). Global market and policy trends for $\mathrm{CO} 2$ in refrigeration. International Journal of Refrigeration, 107, 98-104. https://doi.org/10.1016/j.ijrefrig.2019.08.010

Solomon, S. (1999). Stratospheric ozone depletion: A review of concepts and history. Advancing Earth and Space Science, 37(3), 275-316. https://doi.org/10.1029/1999RG900008

Takita, Y., \& Ishihara, T. (1998). Catalytic decomposition of CFCs. Catalysis Surveys from Asia, 2, 165-173. https://doi.org/10.1023/A:1019094828720

Tokuhashi, K., Urano, Y., Horiguchi, S., \& Kondo, S. (1990). Incineration of CFC-12 by Burner Methods. Combustion Science and Technology, 72(1-3), 117-129. https://doi.org/10.1080/00102209008951643

UNEP (United Nations Environment Programme). (2002). Montreal Protocol on Substances that Deplete the Ozone Layer. Report of the Technology and Economic Assessment Panel. 3B. UNEP publishing. Retrieved June 16, 2020, from https://ozone.unep.org/sites/default/files/2019-05/TEAP02V3b\%20\%281\%29.pdf/

UNEP (United Nations Environment Programme). (2018). Montreal Protocol on Substances that Deplete the Ozone Layer. Report of the Technology and Economic Assessment Panel. 2. UNEP publishing. Retrieved June 16, 2020, from https://ozone.unep.org/sites/default/files/2019-04/TEAP-DecXXIX4-TF-ReportApril2018.pdf

Urano, K., Kato, M., Kimura, C., \& Tasaki, T. (1997). Decomposition of CFCs/HCFC in an industrial waste incineration facility; Kakushu freon no sangyo haikibutsu shokyaku shisetsu deno bunkai. Taiki Kankyo Gakkaishi, 32(5), 331-340 (in Japanese). https://doi.org/10.11298/taiki1995.32.5_331

USEPA (United States Environmental Protection Agency). (2008). Combustion Equipment. Presentation at MACT EEE Training Workshop. US EPA Archive Document. Retrieved June 16, 2020, from https://archive.epa.gov/region6/6pd/rcra_c/pd-o/web/pdf/a3-combustionequipment.pdf/

World Bank. (2018). What a Waste 2.0 A Global Snapshot of Solid Waste Management to 2050. World Bank Group publishing. Retrieved June 16, 2020, from https://openknowledge.worldbank.org/handle/10986/30317/

Yazici, B., Can, X. S., \& Calli, B. (2014). Prediction of future disposal of end-of-life refrigerators containing CFC11. Waste Management, 34(1), 162-166. https://doi.org/10.1016/j.wasman.2013.09.008

Yoneda, K., Ikeguchi, T., Yagi, Y., Tamade, Y., \& Omori, K. (2002). A research on dioxin generation from the industrial waste incineration. Chemosphere, 46(9-10), 1309-1319. https://doi.org/10.1016/S00456535(01)00246-6

Zeng, X., Duan, H., Wang, F., \& Li, J. (2017). Examining environmental management of e-waste: China's experience and lessons. Renewable and Sustainable Energy Reviews, 72, 1076-1082. https://doi.org/10.1016/j.rser.2016.10.015

\section{Note}

Note 1. Refrigerants Recycling Promotion and Technology Center in Japan sets quality standards for recovered fluorocarbons. For example, the quality standards of HCFC- 22 are $\geq 99.78 \%$ purity, $\leq 20 \mathrm{ppm}$ moisture, $\leq 1 \mathrm{ppm}$ acidity, $\leq 100 \mathrm{ppm}$ vapor residue, colorless, no turbid and no stench. 


\section{Copyrights}

Copyright for this article is retained by the author(s), with first publication rights granted to the journal.

This is an open-access article distributed under the terms and conditions of the Creative Commons Attribution license (http://creativecommons.org/licenses/by/4.0/). 